\title{
NILAI SIMBOL CANDI BOROBUDUR DALAM WISATA KAPITALIS GLOBAL
}

\author{
Tri Yatno \\ S3 Kajian Budaya Universitas Sebelas Maret Surakarta \\ triyatno2410@gmail.com
}

\begin{abstract}
Abstrak
Candi Borobudur sebagai warisan agama Buddha menjadi simbol budaya yang memiliki nilai estetika dan spiritual. Negara memiliki peran sentral dalam mengelola Candi Borobudur sebagai bagunan cagar budaya dan pariwisata. Penelitian ini bertujuan untuk menganalisis nilai simbol religi pada Candi Borobudur dalam wisata kapitalis global. Metode penelitian ini menggunakan pendekatan studi kasus dalam mengungkap permasalahan. Hasil penelitian manyatakan bahwa Candi Borobudur memiliki nilai jual sebagai material pariwisata. Simbol-simbol religi Buddha di Candi Borobudur dikomodifikasi menjadi komoditas wisata. Dampak dibukanya Candi Borobudur sebagai komoditas wisata memiliki dampak positif dan negatif bagi kehidupan beragama dan bermasyarakat
\end{abstract}

Kata kunci: Nilai, Simbol, Borobudur, Wisata, Kapitalis

\section{Abstract}

Borobudur Temple is a Buddhist heritage. It is a cultural symbol has aesthetic and spiritual values. The state has a central role in managing Borobudur Temple as a cultural heritage building and tourism. This study aims to analyze the religious symbols in Borobudur Temple in global capitalist tourism. This research method uses a case study approach in uncovering the problem. The results of the research state that Borobudur Temple has a selling value as a tourism material. Buddhist religious symbols in Borobudur Temple are commodify into tourism commodities. The impact of the opening of Borobudur Temple as a tourist commodity has a positive and negative impact on religious and social life

Keywords: Value, Symbol, Borobudur, Tourism, Capitalist

\section{PENDAHULUAN}

Borobudur merupakan candi

Buddha yang sangat fenomenal dan menjadi simbol bangsa Indonesia. Borobudur merupakan hasil karya masyarakat Buddha yang mempunyai nilai-nilai estetika, budaya, seni, arsitektur, dan spiritual. Borobudur berbentuk stupa yang mempunyai nilai sakral dan dijadikan tempat pemujaan. Di balik wujud candi Borobudur tampak ada tatanan atau aturan yang dipakai 


\section{Sabbhata Yatra}

Jurnal Pariwisata dan Budaya

Volume 1 Nomor 2 Desember 2020

panduan yang menunjuk adanya relasi antara komponen-komponen dalam mewujudkan arsitektur candi yang terstruktur. Penataan candi yang terstruktur mempunyai nilai seni dan nilai spiritual tinggi sebagai lambang kehidupan manusia dan kehidupan setelah kematian.

Selain memiliki nilai spiritual, Candi Borobudur sebagai cagar budaya mempunyai nilai jual dalam bidang pariwisata. Seperti yang dikutip dalam Inews.id tanggal 14 September 2019 bahwa Borobudur masuk dalam lima destinasi super prioritas diantara sepuluh destinasi wisata bali baru yang diusulkan. Kondisi ini menjadikan Candi Borobudur dalam oposisi biner yakni satu sisi mengedepankan spiritual agama Buddha, sisi lainnya menitiberatkan pada bidang pariwisata sebagai komoditas.

Pengembangan candi Borobudur sebagai objek wisata diharapkan dapat menambah kesejahteraan masyarakat sekitar, diantaranya melalui pemanfaatan simbol agama Buddha sebagai bentuk komoditas baik dilakukan oleh industri pariwisata, industri jasa maupun para pedagang sebagai ciri khas daerah wisata candi. Kondisi ini menjadikan kawasan candi
Borobudur sebagai ruang interaksi antara industri pariwisata, pedagang, dan wisatawan dalam pemenuhan kebutuhan dan kepuasan melalui komodifikasi. Komodifikasi nilai spiritual candi Borobudur, diantaranya Stupa dan Simbol Buddha dijadikan seni asbak atau tempat putung rokok, candi Borobudur digunakan sebagai tempat fasion, dan tempat foto prewed, yang kesemuanya lebih mengedepankan seni yang mempunyai nilai jual dan mengesampingkan nilai kesakralan.

Berdasarkan kondisi tersebut bahwa saat ini Candi Borobodur telah mempunyai fungsi ganda, yakni satu sisi digunakan oleh umat Buddha dalam melakukan ritual keagamaan, sisi lainnya sebagai objek wisata. Fungsi ganda tersebut melahirkan sudut pandang yang berbeda pula dalam melihat material candi, yakni satu sisi mengandung nilai religiunitas sisi lainnnya memandang candi sebagai objek pemenuhan napsu selera. Sisi religiunitas terlihat ketika umat Buddha melakukan kegiatan keagamaan, seperti perayaan Waisak, sedangkan candi digunakan sebagai pemenuhan napsu selera diantaranya candi sebagai media pariwisata, media pembelajaran, media foto selfi, ataupun tempat berpacaran. 


\section{Sabbhata Yatra}

Jurnal Pariwisata dan Budaya

Volume 1 Nomor 2 Desember 2020

Hal ini berdampak pada menurunnya

Komodifikasi menurut George

nilai-nilai religi Buddha diantaranya naik candi menggunakan alas kaki dan adanya perilaku kurang sopan dalam memperlakukan simbol Buddha.

Candi Borobudur sebagai simbol agama Buddha telah menjadi situs warisan dunia (World Heritage Site) milik UNESCO, sehingga pemerintah menetapkan legitimasi pengelolaan candi melalui Undang-Undang Nomor 11 Tahun 2010 tentang Cagar Budaya, dimana candi merupakan kategori bangunan situs yang dikelola oleh pemerintah. Tata ruang candi kawasan Borobudur dan sekitarnya diatur dalam Peraturan Presiden Nomor 58 Tahun 2014. Sedangkan dalam rangka pengembangan kawasan pariwisata, merujuk pada Peraturan Presiden Nomor 46 Tahun 2017 tentang Pembentukan Badan Otorita Pengelola Kawasan Pariwisata Borobudur, hal ini menjadikan Borobudur sebagai material wisata kapitalis. Berdasarkan permasalahan tersebut peneliti meneliti terkait bagaimana nilai simbol Candi Borobudur dalam wisata kapitalis global?

\section{Komodifikasi}

Ritzer (2008: 144) berasal dari commodity, yang berarti benda komersial atau objek perdagangan. Jadi komodifikasi nilai agama yang dilakukan di kawasan Candi Borobudur adalah komersialisasi terhadap simbolsimbol agama Buddha menjadi komoditas yang dapat diperjualbelikan untuk mendapat keuntungan.

Permasalahan komodifikasi tidak terlepas dari faktor ekonomi, seperti hasil penelitian Thiago Duarte Pimental yang menganalisi mengenai Bourdieu, Tourism Field and Its Implications for Governance of Tourist Destinations dimana dalam bidang pariwisata setidaknya mempunyai (a) habitus, yakni dalam pariwisata nilai kebutuhan memperluas pengetahuan dan pengalaman yang terkandung sebagai kebutuhan untuk mendapatkan informasi mengenai benda, tempat, dan orang baru. (b) Arena, dalam praktik sosial wisata yang diberikan oleh produsen, badan pengatur, perantara organisasi dan orang-orang atau organisasi tidak berkaitan dengan pariwisata tetapi barang dan jasa. (c) doxa, mengacu pada opini konsensual tentang pariwisata dan perjalanan. Doxa tentang pariwisata bisa lihat dengan gagasan bahwa perjalanan 


\section{Sabbhata Yatra}

Jurnal Pariwisata dan Budaya

Volume 1 Nomor 2 Desember 2020

adalah satu kebutuhan manusia dan pariwisata adalah cara pengetahuan dan meningkatkan potensi manusia. (d) nomos di mana perjalanan adalah formulir untuk mendapatkan modal budaya (Pimental, 2017).

Dalam konteks pariwisata spiritual, Grusendorf dalam penelitiannya yang berjudul Bourdieu's Field, Capital, and Habitus in Religion menyatakan bahwa. Konsep habitus Bourdieu dapat diartikan bahwa agama dalam beberapa kasus menjadi bentuk gaya hidup. Agama adalah ruang privat. Agama adalah bentuk kepercaayaan. Agama adalah gaya hidup yang harus dianut. Ketiga bentuk agama ini membantu organisasi keagamaan untuk lebih memahami dalam penyebaran agama atau dahwah (Grusendorf, 2016).

Hal ini didukung oleh Suatama bahwa komodifikasi spiritual menjadi fakta yang tak terhindarkan dalam modernisasi yang didorong oleh ideologi ekonomi. Dalam proses komodifikasi, nilai tukar mendominasi nilai guna sehingga wacana irasional dimanipulasi dan berperan untuk mendapatkan simpati publik. Ambivalensi moralspiritual tidak dapat dihindari dalam komodifikasi. Dalam hal ini, nilai-nilai moral dan spiritual dinegosiasikan sebagai kepentingan material melalui praktik wacana. Habitus inilah yang dinegosiasikan dengan pusat penyembuhan Usada Bali, baik ekonomi, simbolik dan budaya (Suatama, 2019).

Komodifikasi spiritual lainnya ditulis oleh Daniels dalam penelitiannya yang berjudul The fame of Miyajima Spirituality, commodification and the tourist trade of souvenirs in Japan. Dalam penelitiannya didapat bahwa Bourdieu menganalisi mengenai stratifikasi budaya. Budaya konsumsi menjadi objek modal. Budaya menurut Bourdieu bersifat organik seperti aristokrasi budaya, status sosial yang jelas. Tidak ada strata sosial yang memiliki pola konsumsi secara otomatis memenuhi syarat sebagai budaya yang sah kecualikan terjadi alienasi (Daniels, 2001). Berbagai bentuk dan pengertian komodifikasi tersebut sebagai acuan pembahasan komodifikasi nilai religi Buddha yang ada di Kawasan Candi Borobudur

\section{Industri Budaya}

Berbeda dengan pendapat Adorno bahwa industri budaya mengakibatkan perubahan dalam 


\section{Sabbhata Yatra}

Jurnal Pariwisata dan Budaya

Volume 1 Nomor 2 Desember 2020

karakter seni. Budaya dalam industri budaya adalah komoditas paradoks yang melunturkan nilai-nilai seni. Budaya menjadi industri karena lebih mementingkan keuntungan besar daripada meminati nilai sebagai bentuk kritis dan kebebasan manusia. Seni telah menjadi komoditas dalam pasar yang berarti seni tidak lagi dipandang sebagai high culture, tetapi low culture. Akibatnya, nilai-nilai artistik seni direduksi sehingga menjadi komersial. Produksi budaya mengalami perubahan dari nilai-nilai guna menjadi nilai tukar yang berarti semua produksi budaya hanya memiliki nilai sejauh itu bisa ditukar, tidak sejauh itu adalah sesuatu dalam dirinya sendiri. Di tengah era kecanggihan teknologi dan perkembangan informasi, semakin banyak produk budaya yang 'dijual' secara terang-terangan. Selama 24 jam stasiun televisi berlomba-lomba menyediakan program menarik untuk merebut hati jutaan pemirsa demi sebuah rating atau share yang fantastis. Industri musik pun berjalan tidak lagi sesuai dengan idealisme musisinya, melainkan ada mekanisme pasar yang dibentuk oleh pemodal dan wajib dipenuhi. Begitu pula dengan dunia layar lebar yang cenderung lesu apabila tidak mengikuti selera konsumen. Semua hal tersebut dilakukan tidak lain demi mendapatkan keuntungan sebesar-besarnya bagi segelintir pemilik modal yang bergerak di industri hiburan (Reksa, 2015: 95)

Adorno menyatakan bahwa budaya popular adalah serupa dengan sebuah pabrik yang memproduksi barang standar budaya, kenikmatan yang mudah tersedia melali konsumsi budaya populer membuat orang patuh dan tidak protes, tidak peduli apakah keadaan ekonomi mereka sulit. Budaya industri memunculkan dan menumbuhkan kebutuhan palsu, yaitu kebutuhan dan kepuasan yang dibuat oleh kapitalisme (Hereyah, 2011, 96)

Menurut Adorno, entitas tipikal industri budaya tidak lain adalah komoditas; sebuah komoditas dari awal hingga akhir, dari proses produksi, distribusi, hingga penjualan. Intinya, industri budaya secara langsung sangat membutuhkan tindakan-tindakan kreatif untuk mendatangkan keuntungan sebagai asalmuasal keberadaannya. Keuntungan secara finansial menjadi tujuan dalam ideologinya serta menjadi wilayah independen dari kekuatan penjualan komoditas kultural yang harus diperoleh dengan segala cara. Oleh karena itu 


\section{Sabbhata Yatra}

Jurnal Pariwisata dan Budaya

Volume 1 Nomor 2 Desember 2020

industri budaya berubah menjadi "relasi publik" tanpa harus memperhatikan perusahaan-perusahaan yang memproduksinya ataupun objek-objek yang bisa dijual. Hal itulah yang menjadikan iklan sebagai penopang utama dari distribusi industri budaya dan menjadikan komoditas kultural seolaholah menjadi milik dari iklan itu sendiri. Konsumen tidak lagi memperhatikan perusahaan mana yang memproduksi ataupun bagaimana sebenarnya karakteristik, mutu, dan fungsi komoditas yang diiklankan, tetapi mereka membeli semata-mata karena iklan yang begitu impresif dan menyentuh. Dengan kata lain, konsumen sebenarnya tidak membeli produk, tetapi membeli citra yang diiklankan. Sebagai sebuah komoditas, produk-produk yang dihasilkan industri budaya mempunyai karakteristik yang mengedepankan apa yang disebut standardisasi dan teknik distribusi, dengan hanya sedikit memberi perhatian pada proses produksi yang bermutu (Adorno, 1997)

Menurut Madzhab Frankfurt, industri budaya merefleksikan konsolidasi dari komoditas fetis (commodity fetishism) dan dominasi dari pertukaran nilai monopoli kapital. Komoditas yang diproduksi oleh industri budaya dibentuk dengan kesadaran penuh tentang sebesar apakahnya nilainya di pasar. Motif keuntungan sangat jelas hingga memerlukan standardisasi. Salah satu contohnya adalah sistem bintang di Hollywood (Dominic 1995).

\section{Globalisasi}

Proses globalisasi sudah terjadi sejak masuknya agama Hindu, Budha atau Islam ke nusantara, proses ini bisa dimaknai sebagai salah satu bentuk globalisasi. Pada masa itu sekat-sekat yang membatasi wilayah dan kebudayaan nusantara terbuka dan pada akhirnya terjadi alkulturasi budaya dengan nilai-nilai yang ada pada agamaagama tersebut. Akan tetapi, pada konteks globalisasi dalam dunia komunikasi, globalisasi bertumbuh seiring sejalan dengan perkembangan teknologi informasi dan teknologi komunikasi (Briggs dan Burke, 2006). Globalisasi merupakan kecenderungan masyarakat untuk menyatu dengan dunia, terutama di bidang ilmu pengetahuan, teknologi, dan media komunikasi massa (Surahman, 2013: 30). Globalisasi tidak hanya terjadi pada bidang ekonomi dan politik, namun juga 


\section{Sabbhata Yatra}

Jurnal Pariwisata dan Budaya

Volume 1 Nomor 2 Desember 2020

terjadi pada aspek lain, salah satunya aspek budaya. (Larasati, 2018: 112)

Di tengah interkoneksi global masyarakat menegakkan identitas diri menjadi sesuatu yang sulit sekaligus paradoks. Gerakan-gerakan sosial kemasyarakatan kini praksis terjebak dalam lingkaran interkoneksi global . Masyarakat yang sedang bergerak ini terus mencari konstruksinya sendiri di tengah bentangan dunia sebagai pasar global. Gerakan-gerakan sosial mewakili komunitas tempatan, adat, atau revitalisasi kebudayaan kadang tidak terlepas dari penetrasi kuasa global kapital ini (Suryawan, 2011: 157) termasuk dalam pariwisata kawasan candi Borobudur yang telah terkoneksi global

\section{METODE}

Penelitian ini menggunakan pendekatan studi kasus dalam menganalisis simbol-simbol religi Buddha yang dijadikan komoditas wisata dalam pusaran kapitalis global. Data penelitian ini menggunakan data primer dan sekunder dalam mengungkap isu-isu terkait permasalahan simbol religi dan pariwisata. Data yang telah terkumpul dianalisis dan disimpulkan sebagai hasil penelitian.

\section{PEMBAHASAN}

Nilai Spiritual Candi Borobudur

Nilai spiritual merupakan konsep abstrak yang dianggap penting mengenai kode etik kehidupan mengenai baik buruk dan benar salah yang didasarkan pada kepercayaan kepada Tuhan. Nilai spiritual bersifat individual dan merupakan milik pribadi yang paling dalam. Dalam agama Buddha, nilai spiritual digambarkan dalam bentuk simbol, baik yang bersifat nyata maupun abstrak. Salah satu bentuk nyata nilai spiritual Buddha terdapat pada Candi Borobudur. Umat Buddha melihat candi Borobudur sebagai objek sakral (objek Puja) dimana Borobudur melambangkan adanya alam semesta. Borobudur sebagai kitab suci visual yang menggambarkan tiga alam kehidupan, yakni kamadhatu, rupadhatu, dan arupadhatu. Demikian juga dengan candi-candi lain merupakan tempat untuk melakukan Puja yang memiliki nilai filosofis sakral. Pemujaan terhadap candi bukan berarti menyembah berhala, namun candi sebagai obyek meditasi (perenungan) bahwa kehidupan ini tidak kekal (anicca). Selama makhluk masih diselimuti oleh keinginan napsu (tanha) maka siklus kelahiran kembali di 31 


\section{Sabbhata Yatra}

Jurnal Pariwisata dan Budaya

Volume 1 Nomor 2 Desember 2020

alam kehidupan masih terjadi, namun jika makhuk telah melenyapkan tanha maka telah mampu merealisasikan Nibbana.

Candi Borobudur sebagai bukti kejayaan pemerintahan Wangsa Syailendra di Nusantara, pembangunan candi sebagai tanda adanya kemakmuran, keharmonisan serta spiritual tinggi, mulai dari raja sampai dengan rakyat jelata, sebab membangun candi, seperti Borobudur membutuhkan pengetahuan luas, dana besar dan solidaritas yang kuat dalam mewujudkan bangunan sakral candi untuk ritual keagamaan. Runtuhhnya Wangsa Syailendra membentuk peradaban baru dan pandangan baru terhadap candi Borobudur, yakni telah terjadi pergeseran nilai guna menjadi nilai tukar. Kondisi ini menggambarkan bahwa telah terjadi komodifikasi nilai spiritual Buddha pada kawasan Candi Borobudur sebagai wisata kapitalis, diantaranya masyarakat sekitar memanfaatkan candi sebagai lahan pekerjaan industri yakni candi Borobudur dijadikan material komoditas yang dapat dikomodifikasikan.

Bentuk komodifikasi Candi Borobudur sebagai bentuk pengembangan seni dari manusia dalam menarik wisatawan untuk menempatkan candi Borobudur sebagai objek pariwisata spiritual yang mempunyai ciri khas agama Buddha. Pengembangan seni tersebut berupa seni pahat, seni lukis, sablon maupun seni ukir dari simbol-simbol spiritual Buddha diantaranya adalah pembuatan miniatur candi, miniatur stupa, patung Buddha, serta kaos, dan tas yang bercirikan agama Buddha. Komodifikasi simbol spiritual Buddha tersebut dijadikan bahan souvenir bagi para industri wisata.

\section{Pergeseran nilai spiritual dalam} Komodifikasi

Pergeseran nilai spiritual Buddha dalam komodifikasi simbol agama Buddha mempunyai dampak positif dan negatif. Dampak positif dari komodifikasi simbol agama Buddha yang ada di Kawasan Candi Borobudur tentunya mansyarakat lebih mengenal terkait simbol-simbol agama Buddha. Namun dalam perkembanganya industri pariwisata khususnya yang bergerak dalam bidang seni mempunyai pandangan yang berbeda terkait simbolsimbol dalam candi.

Simbol candi yang dikemas dalam bentuk souvenir yang mengalami pergeseran nilai spiritual Buddha 


\section{Sabbhata Yatra}

Jurnal Pariwisata dan Budaya

Volume 1 Nomor 2 Desember 2020

diantaranya adalah pembuatan minatur candi Borobudur, miniatur stupa, dan rupang Buddha dijadikan sebagai asbak tempat putung rokok. Dalam kasus ini komodifikasi seniman telah menempatkan simbol religi Buddha pada kondisi yang kurang pantas, sehingga melalui tulisan ini dapat dijadikan referensi dalam mengkomodifikasikan simbol agama. Selain itu terdapat juga industri pariwisata yang membuat asesoris liontin dengan menggunakan kepala Buddha. Dalam konteks Buddhisme kepala Buddha mempunyai arti ketidakkekalan, namun ketika kepala Buddha digunakan sebagai liontin yang dikalungkan, memiliki tafsir lain bahwa Buddha telah dipenggal kepalanya kemudian digantung. Hal ini juga termasuk perilaku yang kurang pantas jika dipandang dalam spiritual Buddha. Seni dan religi memiliki perspektif yang berlawanan. Dimana seni mengedepankan popularitas yang diikuti oleh keuntungan material berupa uang, namun religi mengedepankan kesakralan yang diikuti oleh pembebasan keinginan napsu.

Bentuk komodifikasi religi Buddha lainnya adalah Patung Buddha yang diperdagangkan terdiri dari: Buddha tidur, Buddha posisi meditasi,
Buddha posisi berdiri, dan kepala Buddha. Berbagai macam jenis patung Buddha yang diperdagangkan tentunya dapat menarik pembeli untuk memilikinya sebagai kenang-kenangan pernah pergi ke Candi Borobudur. Bentuk komodifikasi yang terdapat di Candi Borobudur merupakan sebuah fenomena yang terjadi sejak kawasan Candi Borobudur dibuka menjadi kawasan wisata.

\section{Dampak dari komodifikasi} simbol religi Buddha di era globalisasi diantaranya dapat mengenalkan simbolsimbol agama Buddha kepada masyarakat dunia melalui sektor pariwisata dan industri kreatif. Globalisasi mempunyai idiologi kapitalis telah membuka ruang bagi industri kreatif dalam mengeksplor ideide dan gagasannya dan diharapkan mampu bersaing dengan pasar dunia, dimana Globalisasi tidak terlepas dari perkembangan ilmu dan teknologi.

\section{Wisata Kapitalis Global Candi Borobudur}

Candi Borobudur telah menjadi warisan dunia yang dikelola melalui sektor wisata. Pariwisata Candi Borobudur berkembang dengan sangat cepat dibanding dengan candi-candi 


\section{Sabbhata Yatra}

Jurnal Pariwisata dan Budaya

Volume 1 Nomor 2 Desember 2020

Buddha di sekitar candi Borobudur. Hal ini tidak terlepas dari pengaruh teknologi informasi.Perkembangan teknologi yang sangat pesat dalam dunia industri adalah media internet. Melalui media internet informasi komodifikasi simbol religi Buddha dengan cepat mampu menjangkau ke seluruh masyarakat dunia. Jaringan sosial yang dikembangkan oleh industri pariwisata dan industri kreatif menjadikan transaksi ekonomi melalui jaringan sosial.

Kapitalis global pada wisata candi Borobudur menjadikan internet sebagai media jaringan sosial dalam mempromosikan simbol-simbol agama Buddha, baik yang mempunyai nilai spiritual maupun yang telah terkomodifikasi. Media berjasa memperkenalkan artefak budaya Buddha kepada masyarakat luas, sehingga masyarakat sadar akan keindahan dan keistimewaan candi Borobudur. Di sisi lain media berperan dalam menyebarkan diskursus konsumsi sehingga komodifikasi nilai simbol religi Candi Borobudur sedemikian meluas menjangkau artefak budaya.

Melalui sektor pariwisata Candi Borobudur lebih dikenal oleh masyarakat dunia, diantaranya melalui event-event seni budaya dan kegiatan religi Buddha. Sebagai tempat ibadah umat Buddha yang terbesar di seluruh dunia, Borobudur menjadi salah satu hasil budaya manusia yang paling sering dikunjungi lebih dari sejuta wisatawan setiap tahunnya. Baik domestik maupun mancanegara. Tidak ada satupun candi di seluruh dunia yang menyerupai gaya arsitek candi ini.

Adanya objek wisata Candi Borobudur mepunyai berpengaruh positif terhadap perilaku sosial ekonomi di antaranya adanya pemasukan devisa negara, terbukanya lapangan pekerjaan, meluasnya kesempatan usaha, daan meningkatkan pola pikir kreatif dalam pengembangan pariwisata, lebih dikenalnya sibol-simbol religi Buddha oleh masyarakat dunia. Sedangkan pengaruh negatifnya antara lain adanya persaingan usaha pariwisata maupun industri kreeatif serta para pedagang di kawasan Candi Borobudur, terjadi komodifikasi nilai simbol religi Buddha, terjadi pergeseran nilai kesakralan akibat komodifikasi.

Komodifikasi nilai yang terjadi di Kawasan Candi Borobudur senada dengan pendapat Bourdieu dalam penelitian Daniels, yakni budaya konsumsi menjadi objek modal dalam 


\section{Sabbhata Yatra}

Jurnal Pariwisata dan Budaya

Volume 1 Nomor 2 Desember 2020

pariwisata spiritual. Melalui

komodifikasi menjadi daya tarik tersendiri bagi wisatawan dalam menikmati keindahan dan keunikan candi Borobudur, meskipun satu sisi terjadi pergeseran terhadap nilai simbol religi Buddha di Kawasan Candi Borobudur. Pergeseran nilai tersebut diantaranya candi Borobudur bukan lagi sebagai wisata spiritual namun lebih mengarah pada pemenuhan napsu selera, selain itu Candi Borobudur saat ini lebih condong sebagai media pembelajaran daripada media spiritual. Kondisi ini hendaknya menjadi perhatian khusus bagi pemerintah dalam pengelolaan Candi Borobudur, dimana satu sisi berpihak pada wisata kapitalis, satu sisi harus berfikir pada kehidupan beragama.

\section{PENUTUP}

Berdasarkan pembahasan yang telah dilakukan, diperoleh kesimpulan bahwa nilai spiritual Candi Borobudur digambarkan dalam bentuk simbol-sibol kehidupan alam semesta, baik yang bersifat nyata maupun abstrak, umat Buddha melihat candi Borobudur sebagai objek sakral untuk melakukan Puja. Candi Borobudur merupakan warisan dunia yang mepunyai nilai seni tinggi dan nilai jual sebagai material pariwisata. Sejak dibukanya menjadi objek wisata mulai terjadi komodifikasi nilai simbol agama Buddha, diantaranya seni pahat, seni ukir, dan seni lukis yang mempunyai dampak positif dan negatif dalam persaingan sektor pariwisata kapital global. Hal ini dapat dijadikan rujukan oleh pemerintah maupun industri pariwisata untuk lebih memonitor bentuk komodifikasi nilai religi Buddha di kawasan Candi Borobudur agar tidak ada pihak yang dirugikan dan memiliki manfaat yang positif

\section{DAFTAR PUSTAKA}

Adorno, Theodor W. 1997. "Culture Industry Reconsidered". Media Studies: A Reader. Edinburgh: Edinburgh University Press

Daniels. 2001. The fame of Miyajima Spirituality, commodification and the tourist trade of souvenirs in Japan

Dominic, Strinati.1995. An Introduction tso Theories of Popular Culture. London: Routledge

Grusendorf. 2016. Bourdieu's Field, Capital, and Habitus in Religion. Journal for the Sociological Integration of Religion and Society Volume 6, No. 1 • Spring 2016

Hereyah, Yoyok. 2011. Media Massa: Pencipta Industri Budaya Pencerahan yang Menipu Massa 


\section{Sabbhata Yatra}

Jurnal Pariwisata dan Budaya

Volume 1 Nomor 2 Desember 2020

Studi Simulacra dan Hiperrealitas Film AVATAR. UMN Volume III, Nomor 2• Desember 2011

Larasati, Dinda. 2018. Globalisasi Budaya dan Identitas: Pengaruh dan Eksistensi Hallyu (KoreanWave) versus Westernisasi di Indonesia. Jurnal Hubungan Internasional $\square$ Tahun XI, No.1, Januari - Juni 2018

Pimental, Thiago Duarte. 2017. Bourdieu, Tourism Field and Its Implications for Governance of Tourist Destinations. Rev. Anais Bras. de Est. Tur./ ABET, Juiz de Fora, v.7, n.2, p.32 - 37, Maio/Ago., 2017

Reksa, Abdul Fitri Angga. Kritik Terhadap Modernitas: Dialectic Of Enlightenment Theodor $W$. Adorno dan Max Horkheimer. California: Stanford University Press,

Ritzer, George. 2008. Teori Sosial PostModern. Yogyakarta, Kreasi Wacana.
Suatama, Ida Bagus. 2019. Commodification of Usada Bali:Between Profit-oriented and Negotiation of Sasana Balian. International Journal of Social Sciences and Humanities. Vol. 3 No. 2, August2019, pages: 136 144

Suryawan, I Ngurah. 2011. Teater GloBALIsme: Pariwisata, Interkoneksi Global, dan Nasib Manusia Bali di Garis Depan. Jurnal Kajian Bali Volume 01, Nomor 01, April 2011 